\title{
DIRECT, LONGWAVE RADIATIVE FORCING OF MINERAL DUST: IMPROVEMENT OF ITS ESTIMATION BY MEANS OF TOOLS RECENTLY DEVELOPED BY THE EARLINET COMMUNITY
}

\author{
Michaël Sicard ${ }^{1,2 *}$, Constantino Muñoz-Porcar ${ }^{1}$, Adolfo Comerón ${ }^{1}$, Alejandro Rodriguez ${ }^{1}$, Francesc \\ Rocadenbosch $^{1,2}$, Ruben Barragan ${ }^{1,2}$
}

\author{
${ }^{1}$ Remote Sensing Laboratory, Universitat Politècnica de Catalunya, Barcelona, Spain, *Email: \\ msicard@tsc.upc.edu
}

${ }^{2}$ Ciències i Tecnologies de l'Espai - Centre de Recerca de l'Aeronàutica i de l'Espai / Institut d'Estudis Espacials de Catalunya (CTE-CRAE / IEEC), Universitat Politècnica de Catalunya, Barcelona, Spain

\begin{abstract}
The objective of this work is to investigate how the knowledge of the vertically-resolved fine and coarse mode aerosol optical depth modifies the longwave radiative forcing. Since relatively little the EARLINET (European Aerosol Research Lidar Network) community has developed codes that combine sun-photometer and lidar data to retrieve a set of parameters vertically-resolved related to the size distribution (fine and coarse mode extinction coefficients, fine and coarse mode volumetric concentrations, etc.). We concentrate on the case of mineral dust whose size distribution is often dominated by the coarse mode. This work demonstrates that the knowledge of the vertically-resolved fine and coarse mode aerosol optical depth modifies the LW RF as compared to the classical approach with a unique profile of total aerosol optical depth. The results show that when the coarse mode predominates the classical approach underestimates the dust longwave radiative forcing by 10 to $20 \%$ at the surface. The effect at the top of the atmosphere is not systematic because of the predominance of fine particles near the top of the dust layer.
\end{abstract}

\section{INTRODUCTION}

Atmospheric aerosols have a remarkable effect on the Earth-atmosphere radiative budget. Indeed, aerosols and their interactions with clouds contribute to the largest uncertainties in the estimation of the Earth's changing energy budget [1]. Nowadays many radiative transfer models have been developed to locally estimate the aerosol direct radiative forcing (RF) [2][3]. In the longwave (LW) spectral range, the aerosol radiative properties are usually estimated theoretically with a Mie code. The parameter that contains the absorption and scattering quantities, the extinction coefficient, is normalized to the extinction coefficient in the shortwave (SW) spectral range, most of the time in the visible spectral range [4][5], or to the number concentration [6]. As measurements of the extinction coefficient or of its integral, the aerosol optical depth (AOD), are available in the shortwave spectral range, the equivalent extinction coefficient or optical depth in the LW spectral range can be deduced thanks to that normalized, theoretical extinction coefficient.

In this work we use codes recently developed by the EARLINET community to separate the contributions of the small and the large particles. It is known that for a constant value of extinction in the visible spectral range, the theoretical extinction value in the LW spectral range (calculated with a Mie code) will vary with particle size. It is then expected that considering small and large particles separately will give extinction values in the LW different than considering the total bimodal distribution as a whole. This work investigates how the knowledge of the vertically-resolved fine and coarse mode AOD modifies the LW RF usually estimated with a single profile of total AOD.

\section{METHODOLOGY}

Irradiances in the longwave spectral region are calculated using the GAME code [7]. The generic parameters used as input in the Mie code (particles' shape, refractive index, size 
distribution and density) and in GAME (atmospheric pressure, temperature and relative humidity, and surface albedo) are described in [5] and [8].

To estimate the aerosol RF in the LW spectral range the profile of the LW AOD is calculated by multiplying the SW AOD profile to the normalized LW extinction coefficient (previously calculated with a Mie code). The single scattering albedo and the asymmetry factor are intensive parameters and are estimated in the LW with a Mie code. In the following, the altitude dependency has been omitted for the sake of clarity.

In the classical approach, a bimodal size distribution (e.g. measured by a sun-photometer) is considered to calculate the normalized LW extinction coefficient, $\bar{\alpha}_{L W, b m}$, and a profile of total $\mathrm{AOD}$ at $532 \mathrm{~nm}, A O D_{532, t}$, (e.g. measured by a lidar) is considered for the SW AOD profile. The profile of the LW AOD is calculated as:

$$
A O D_{L W, \text { class }}=\bar{\alpha}_{L W, b m} A O D_{532, t} \text {. }
$$

In the new approach, called the Mode Separation Profiling (MSP) method like in [8], two monomodal size distributions (e.g. measured by a sunphotometer) are considered to calculate the coarse and fine normalized LW extinction coefficients, $\bar{\alpha}_{L W, \mathrm{c}}$ and $\bar{\alpha}_{L W, \mathrm{f}}$, respectively. Two profiles of coarse and fine $\mathrm{AOD}$ at $532 \mathrm{~nm}, A O D_{532, \mathrm{c}}$ and $A O D_{532, \mathrm{f}}$, (e.g. measured by combining lidar and sun-photometer, see next Section) are considered for the SW AOD profile. The profile of the LW AOD is calculated as:

$$
A O D_{L W, M S P}=\bar{\alpha}_{L W, \mathrm{c}} A O D_{532, c}+\bar{\alpha}_{L W, \mathrm{f}} A O D_{532, f} .
$$

As $\bar{\alpha}_{L W, \mathrm{c}}$ can be larger than $\bar{\alpha}_{L W, b m}$, in cases predominated by large particles it can occur that:

$$
A O D_{L W, \text { class }}<A O D_{L W, M S P} \text {. }
$$

For instance, in the extreme case $A O D_{532, f}=0$, the latter equation is satisfied if $\bar{\alpha}_{L W, b m}<\bar{\alpha}_{L W, \mathrm{c}}$.

In Fig. 1 we plot the LW normalized extinction for the three size distributions: the bimodal and both coarse and fine mono-modal distributions. The input data are the ones of the first case study (see next Section) given in Table 1. It is clearly visible that $\bar{\alpha}_{L W, b m}<\bar{\alpha}_{L W, \mathrm{c}}$ (by a factor of 2 approximately) in the entire spectral range even though over the whole column the fraction of coarse mode AOD (47\%, see Table 1) is lower than the one of fine mode AOD. It results that, even though $A O D_{532, t}>A O D_{532, \mathrm{c}}$, there might be some altitude ranges where the large particles predominate where $A O D_{L W, \text { class }}$ could be lower than $A O D_{L W, M S P}$, implying a modification in the LW RF.

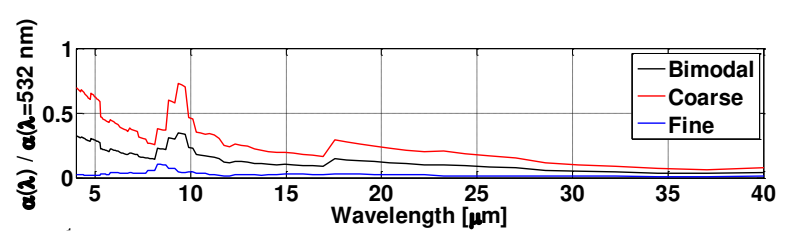

Fig. 1. Normalized extinction coefficient in the LW spectral range for Case 1.

\section{RESULTS}

The code used to estimate separately the coarse and fine mode fractions of the extinction coefficient and volumetric concentration is LIRIC (LIdar-Radiometer Inversion Code) [9]. LIRIC calculates the fine and coarse particle concentration profiles, using the backscattered lidar signals at three wavelengths (355, 532 and $1064 \mathrm{~nm}$ ) and the column averaged aerosol microphysical properties retrieved from a sun photometer. More information about its performances can be found in [10] and [11].

We use a total of four lidar and AERONET sunphotometer measurements in Barcelona with different loads and vertical distributions of mineral dust. Table 1 gives some description of the four cases in terms of AOD and size distribution, as well as the results of our radiative forcing calculations with both the MSP and the classical methods. More details about the mineral dust vertical distribution of those four cases can be found in [8].

At the surface $\Delta F^{M S P}$ ranges from +3.1 to +11.0 $\mathrm{Wm}^{-2}$. All values of $\Delta F^{\text {class }}$ are 10 to $20 \%$ lower than $\Delta F^{M S P}$. The largest difference, $20 \%$, is not 
reached for the case with the highest columnaveraged coarse-to-total AOD fraction but for the case with the highest difference between $\bar{\alpha}_{L W, b m}$ and $\bar{\alpha}_{L W, \mathrm{c}}$ in the bottom part of the mineral dust layer $\left(\bar{\alpha}_{L W, \mathrm{c}}\right.$ is approximately double, see [8]).

At the top of the atmosphere (TOA) the subestimation of $\Delta F^{\text {class }}$ is not systematic. The differences compared to $\Delta F^{M S P}$ range between 16 and $+7 \%$. The overestimation of $\Delta F^{\text {class }}$ of $+7 \%$ occurs for the case with the highest difference between $\bar{\alpha}_{L W, b m}$ and $\bar{\alpha}_{L W, \mathrm{c}}$ in the top part of the mineral dust layer $\left(\bar{\alpha}_{L W, b m}\right.$ is approximately triple, see [8]).

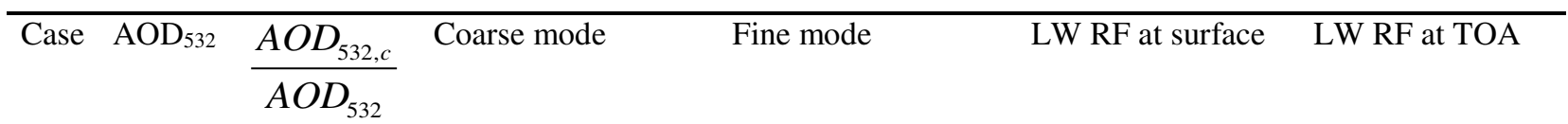

\begin{tabular}{ccccccc} 
& & & $r_{V, c} ; \sigma_{V, c} ; C_{V, c}$ & $r_{V, f} ; \sigma_{V, f} ; C_{V, f}$ & $\Delta F^{M S P} ; \Delta F^{\text {class }}$ & $\Delta F^{M S P} ; \Delta F^{\text {class }}$ \\
& {[]} & {$[\%]$} & {$[\mu \mathrm{m}] ;[] ;\left[\mu \mathrm{m}^{3} \mu \mathrm{m}^{-2}\right]$} & {$[\mu \mathrm{m}] ;[] ;\left[\mu \mathrm{m}^{3} \mu \mathrm{m}^{-2}\right]$} & {$\left[\mathrm{Wm}^{-2}\right]$} & {$\left[\mathrm{Wm}^{-2}\right]$} \\
\hline 1 & 0.19 & 47 & $1.708 ; 0.631 ; 0.066$ & $0.152 ; 0.547 ; 0.018$ & $+3.1 ;+2.8(-10 \%)$ & $+0.6 ;+0.6(0 \%)$ \\
2 & 0.23 & 54 & $1.953 ; 0.588 ; 0.101$ & $0.131 ; 0.503 ; 0.026$ & $+5.4 ;+4.3(-20 \%)$ & $+2.3 ;+2.2(-4 \%)$ \\
3 & 0.23 & 57 & $2.206 ; 0.629 ; 0.112$ & $0.143 ; 0.520 ; 0.020$ & $+4.4 ;+3.7(-16 \%)$ & $+1.5 ;+1.6(+7 \%)$ \\
4 & 0.48 & 72 & $1.809 ; 0.545 ; 0.257$ & $0.117 ; 0.647 ; 0.042$ & $+11.0 ;+9.3(-15 \%)$ & $+5.0 ;+4.2(-16 \%)$ \\
\hline
\end{tabular}

Table 1. LW RF calculated by the MSP and the classical methods, $\Delta F^{M S P}$ and $\Delta F^{\text {class }}$ respectively. The percentage after $\Delta F^{\text {class }}$ is its relative difference with respect to $\Delta F^{M S P} . r_{V}, \sigma_{V}$ and $C_{V}$ represent the columnaveraged volumetric radius, standard deviation and volumetric concentration. The suffixes $c$ and $f$ stand for coarse and fine, respectively.

\section{CONCLUSIONS}

The calculation of mineral dust, and aerosols dominated by large particles in general, direct radiative forcing in the longwave spectral range can be improved when both profiles of coarse and fine mode extinction coefficients can be retrieved separately. Our work demonstrates that the classical method underestimates the LW RF at the surface by 10 to $20 \%$. As the predominance of the large particles decreases with increasing height, this subestimation is not systematic at the TOA. However the strong predominance of large particles at the surface has also an effect on the forcing in the upper layers.

In presence of large particles, the improved estimation of LW RF suggests that the total ( $\mathrm{SW}+\mathrm{LW}$ ) forcing is reduced (since both forcings are usually of opposite sign), and that aerosol impact on regional climate near dust sources could be lower than the actual estimations.

\section{ACKNOWLEDGEMENT}

This work is supported by the 7th Framework Programme project Aerosols, Clouds, and Trace Gases Research Infrastructure Network (ACTRIS) (grant agreement no. 262254). Lidar measurements in Barcelona are supported by the Spanish Ministry of Science and Innovation and FEDER funds under the projects TEC2012-34575, UNPC10-4E-442, CGL2011-13580-E/CLI and CGL2011-16124-E/CLI.

\section{REFERENCES}

[1] IPCC, "Climate Change 2013, The Physical Science Basis", Working Group I Contribution to the Fifth Assessment Report of the Intergovernmental Panel on Climate Change, T.F. Stocker, D. Qin, G.-K. Plattner, M. Tignor, S.K. Allen, J. Doschung, A. Nauels, Y. Xia, V. Bex, and P.M. Midgley (eds.), Chapter 7: Clouds and Aerosols, 571-658, doi: http://dx.doi.org/10.1017/CBO9781107415324.01 6, Cambridge University Press, New York, 2014. 
[2] Ricchiazzi, P., S. Yang, C. Gautier, D. Sowle, 1998: SBDART: A Research and Teaching Software Tool for Plane-Parallel Radiative Transfer in the Earth's Atmosphere, Bull. Am. Meteor. Soc., 79(10), 2101-2114.

[3] Key, J., A. J. Schweiger, 1998: Tools for atmospheric radiative transfer: Streamer and FluxNet, Computers \& Geosciences, 24(5), 443451.

[4] Dufresne, J., C. Gautier, P. Ricchiazzi, 2002: Longwave scattering effects of mineral aerosols, American Meteorological Society, 59, 1959-1966.

[5] Sicard, M., S. Bertolín, M. Mallet, P. Dubuisson, A. Comerón, 2014: Estimation of mineral dust longwave radiative forcing: sensitivity study to particle properties and application to real cases in the region of Barcelona, Atmos. Chem. Phys., 14, 9213-9231.

[6] Sokolik. I. N., O. B. Toon, R. W. Bergstrom, 1998: Modeling the radiative characteristics of airborne mineral aerosols at infrared wavelengths, J. Geophys. Res., 103, 8813-8826.

[7] Dubuisson, P., J. Roger, M. Mallet, O. Dubovik, 2006: A Code to Compute the Direct Solar Radiative Forcing: Application to Anthropogenic Aerosols during the Escompte Experiment, Proc. International Radiation Symposium (IRS 2004) on Current Problems in Atmospheric Radiation, edited by H. Fischer, B.J. Sohn and A. Deepak, Hampton, 127-130.

[8] Sicard M., S. Bertolín, C. Muñoz, A. Rodríguez, F. Rocadenbosch, A. Comerón, 2014: Separation of aerosol fine- and coarse-mode radiative properties: Effect on the mineral dust longwave, direct radiative forcing. Geophys. Res. Lett., 41, doi:10.1002/2014GL060946.

[9] Chaikovsky, A., Dubovik, O., Goloub, P., Tanré, D., Pappalardo, G., Wandinger, U., Chaikovskaya, L., Denisov, S., Grudo, Y., Lopatsin, A., Karol, Y., Lapyonok, T., Korol, M., Osipenko, F., Savitski, D., Slesar, A., Apituley, A., Arboledas, L. A., Binietoglou, I., Kokkalis, P., Granados Muñoz, M. J., Papayannis, A., Perrone, M. R., Pietruczuk, A., Pisani, G., Rocadenbosch, F., Sicard, M., De Tomasi, F., Wagner, J., Wang,
X., 2012: Algorithm and software for the retrieval of vertical aerosol properties using combined lidar/ radiometer data: Dissemination in EARLINET, in: Proceedings of the 26th International Laser and Radar Conference, vol. 1, Porto Heli, Greece, 25-29 June 2012, 399-402.

[10] Wagner, J., A. Ansmann, U. Wandinger, P. Seifert, A. Schwarz, M. Tesche, A. Chaikovsky, O. Dubovik, 2013: Evaluation of the Lidar/Radiometer Inversion Code (LIRIC) to determine microphysical properties of volcanic and desert dust, Atmos. Meas. Tech., 6, 17071724.

[11] Granados-Muñoz, M. J., GuerreroRascado, J. L., Bravo-Aranda, J. A., NavasGuzmán, F., Valenzuela, A., Lyamani, H., Chaikovsky, A., Wandinger, U., Ansmann, A., Dubovik, O., Grudo, J. O., and Alados-Arboledas, L., 2014: Retrieving aerosol microphysical properties by Lidar-Radiometer Inversion Code (LIRIC) for different aerosol types, J. Geophys. Res., 119, 4836-4858. 